\title{
COVID-19's intersectional impact on work life, home life and wellbeing: A mixed-methods analysis of Georgia women's experiences during the pandemic
}

\author{
Megan McCool-Myers ( $\nabla$ megan.myers@emory.edu ) \\ Emory University School of Medicine, Department of Gynecology and Obstetrics \\ Damion Grasso \\ University of Connecticut Health, Department of Psychiatry \\ Debra Kozlowski \\ Emory University School of Medicine, Department of Gynecology and Obstetrics \\ Sarah Cordes \\ Emory University School of Medicine, Department of Gynecology and Obstetrics \\ Valerie Jean \\ Emory University School of Medicine, Department of Gynecology and Obstetrics \\ Heather Gold \\ Emory University School of Medicine, Department of Gynecology and Obstetrics \\ Peggy Goedken \\ Emory University School of Medicine, Department of Gynecology and Obstetrics
}

\section{Research Article}

Keywords: COVID-19, latent class analysis, mixed methods, adverse experience, exposure, female, mental health, intimate partner violence, stress

Posted Date: March 1st, 2022

DOI: https://doi.org/10.21203/rs.3.rs-1171339/v1

License: @ (1) This work is licensed under a Creative Commons Attribution 4.0 International License. Read Full License 


\section{Abstract}

Background: Women have been especially impacted by the COVID-19 pandemic. This study aimed to characterize women's adverse experiences related to their work lives, home lives and wellbeing during the height of the COVID-19 pandemic and to describe demographic differences of those lived experiences.

Methods: Using the validated Epidemic-Pandemic Impacts Inventory, we collected data from reproductive-aged women in the state of Georgia about their exposure to adverse events during the pandemic. A latent class analysis (LCA) was performed to identify subgroups of women with similar endorsement of adverse experiences and describe their sociodemographic/economic characteristics. An optional open-ended question yielded qualitative data that were analyzed and combined with subgroup findings. Data were collected from September 2020 to January 2021.

Results: 423 women aged 18-49 completed the survey, with 314 (74.2\%) providing qualitative responses. The LCA yielded 4 subgroups: (1) the largest subgroup ( $n=150,35.5 \%)$ was characterized by relatively low probability of adverse experiences but high probability of negative changes in mental health and lifestyle; (2) a "caregiving stress" subgroup ( $n=104,24.6 \%)$ had a high probability of challenges with home and work life, including increased conflict with a partner; (3) a "high exposure" subgroup ( $n=46$, $10.9 \%$ ) with high probability of experiencing multiple adversities across domains (e.g., financial insecurity, health challenges, barriers to access to healthcare, intimate partner violence (IPV), and loss of loved ones) and more likely to be racial/ethnic or sexual minority women; and (4) a "low exposure" subgroup ( $n=123,29.1 \%)$ with relatively low probability of adverse experiences across domains. Individuals in subgroups 1 and 4, which had low probabilities of adverse experiences, were significantly more likely to be nonHispanic white. Qualitative insights expanding upon experiences and provided greater context for pandemic-related adversity with dominant themes reflecting stress, family, mental health, financial impact, and adaptation/resilience.

Conclusions: Though many individuals in our sample experienced hardship, minority populations were most impacted by pandemicrelated adverse experiences in work life, home life, and wellbeing. Recovery and future emergency preparedness efforts in Georgia must incorporate support mechanisms for mental health and IPV, focusing especially on the complex needs of racial, ethnic, and sexual minorities.

\section{Background}

At the start of 2020 a novel coronavirus, causing an infectious respiratory disease SARS-CoV-2 (COVID-19), spread globally. As of December 2021, the US had the highest number of reported cases and deaths of any country worldwide (50 million cases, 797,348 deaths).(1) Southeastern US states have been particularly impacted: the state of Georgia has lost nearly 30,000 lives during the pandemic and is ranked $7^{\text {th }}$ nationwide in the rate of deaths per $100,000 .(1,2)$

To reduce the spread of infection in early 2020 , restrictive measures such as school closures, business closures, and reduced social interaction were implemented. These measures significantly impacted the lives of American families,(3) with women experiencing disproportionate effects on their work life, home life, and wellbeing. Job loss rates in Spring 2020 were nearly two times higher for women than men.(4) When schools closed, women took on many additional responsibilities, including even more childcare than usual, assisting with remote learning, and in some cases shifting entirely to homeschooling.(4) With couples and families obligated to stay at home, in many cases with reduced or no work, these existential insecurities contributed to increased intimate partner violence (IPV) towards women. $(5,6)$ These factors and others have negatively impacted women's mental health: in April 2020 rates of depression and anxiety in women were two to three times higher than before the pandemic.(7)

The purpose of this study is to describe Georgia women's pandemic-related adverse experiences in work life, home life and wellbeing through a quantitative and qualitative approach. Our mixed-methods strategy will first identify subgroups of women with shared experiences by way of a latent class analysis and then enrich these findings with qualitative insights from women in each subgroup. 
Characterizing women's experiences in Georgia could inform the development of health services or public health initiatives to support women and their families post-pandemic.

\section{Methods}

Sample

To answer our research question, we conducted a cross-sectional, online survey. Inclusion criteria were: age 18-49, assigned female at birth, and living in Georgia since January 2020. Two million women ages 18-49 live in the state;(8) we selected a sample size of 400 to yield standard errors of $\pm 5 \%$. Emory University Institutional Review Board approved this study on May 19, 2020.

\section{Procedures}

We employed a mixed-methods approach, using data collected through an online survey, to characterize women's adverse outcomes experienced during the COVID-19 pandemic. Data were collected from September 2020 through January 2021. We recruited individuals through two sources: a state-wide network for research volunteers (study invitations sent via email) and social media (respondents targeted through paid advertisements on Facebook, see Additional File 1 for sample advertisement). We used quota sampling to attain similar distributions of demographic characteristics as reported in state estimates; the study team monitored the demographic data and adapted the screener, recruitment strategy, and advertising accordingly. We followed best practice guidelines for reporting results.(9)

Individuals interested in the study were directed to the online survey, administered through HIPAA-compliant software REDCap. Informed consent was obtained from all subjects and/or their legal guardian(s). After completing the screener, they completed the survey questions. The survey entailed multiple-choice and open-ended questions to capture both quantitative and qualitative data. Survey domains included: sociodemographic and economic data, work life, home life, emotional/ physical/ mental wellbeing, and COVID-19 infection. Multiple-choice questions for the quantitative analysis were drawn primarily from the Epidemic-Pandemic Impacts Inventory from Grasso et al.(10) Given the increase in intimate partner violence (IPV) during the pandemic, it was important to incorporate questions about current IPV and lifetime IPV in this survey. $(5,6,11)$ The survey concluded with an open-ended item: "Please describe the impact that the COVID-19 pandemic has had on you and your family," which was used for the qualitative analysis. At conclusion, survey respondents provided their email addresses and were sent an electronic $\$ 5$ gift card as compensation. Resources for domestic violence, substance use, mental health, suicide prevention and family planning were listed at the end of the survey. The final version of the survey is in Additional File 2.

\section{Mixed Methods Analysis}

First, we calculated frequencies and percentages for categorical variables. Multi-category variables were dichotomized to facilitate the quantitative analysis.

Next, we performed a latent class analysis (LCA) to identify different subgroups within populations that share certain outward characteristics. $(12,13)$ Subgroups are referred to as latent groups (or classes).(12) Each individual in a sample can only belong to one class. The LCA was applied in several steps: indicators were entered into the LCA beginning with one class and adding classes incrementally until a unique solution could not be determined with maximum likelihood $(\mathrm{ML})$ methods. Several fit indices were examined and used to determine optimal fit. Information criterion indices include the Bayesian Information Criteria (BIC),(14) Sample Size Adjusted Bayesian Information Criterion,(15) Consistent Akaike Information Criterion,(16) and Approximate Weight of Evidence, (17) which are interpreted such that lower values convey better fit. BIC is the most commonly used and relied upon fit index for comparing models. $(18,19)$ Additionally, the Vuong-Lo-Mendell-Rubin Likelihood Ratio Test $(20)$ and the Bootstrap Likelihood Ratio Test (21) were applied to compare between models; nonsignificant values indicate the model with one additional class is not a statistically improved fit over the current model. The Bayes Factor (BF) $(22,23)$ is interpreted such that a BF of $<3$ is considered weak evidence that the model with one fewer class is superior over the model with one additional class, BF of 3-10 conveys moderate evidence, and BF >10 conveys strong evidence for the model with one fewer class. The approximate correct model probability 
provides an estimate of the probability that a given model is "correct" among the set of tested models under the assumption that one of the models is "correct".(14) Entropy values were used to evaluate the quality of classes and ranged from 0 to 1 , with values closer to 1 representing better separation of classes.(24) Univariate entropy scores were examined to evaluate the relative contribution of individual items in separating classes.

Then, to examine associations between classes and sociodemographic characteristics, we used the Mplus DU3STEP procedure described by Lanza et al.(25) These procedures follow 3 steps: (1) the LCA is estimated without covariates or distal outcomes, (2) the highest probability of class membership is used to assign classes, and (3) associations between class membership and outcomes are estimated with an adjustment based on classification uncertainty. These methods perform well when class separation is sufficient (i.e., entropy >0.60). Alpha was adjusted for pairwise comparisons using the Bonferroni procedure.(26)

Finally, two researchers qualitatively analyzed the responses to the open-ended question on women's experiences during the pandemic. Statements describing mental health problems, additional responsibilities, stress, financial issues, social isolation and/or other pandemic-related challenges were classified as "negative"; statements describing "breaking even" or "counting one's blessings" were considered "neutral"; statements describing improvements were deemed "positive". In a second analysis, themes were iteratively extracted from the responses to create a codebook;(27) multiple themes could be allocated to each response. After independent assessment, the researchers met to discuss and resolve coding discrepancies. We selected anchor quotes to expound upon the experiences of members of each class. We used a Chi-squared test to determine if there was a significant difference in the proportion of classes that responded and those that did not respond to the question.

\section{Results}

Sample characteristics

Of the 436 respondents who started our online survey, 13 screened out or did not complete the survey, yielding a final sample of 423 (97.0\% completion rate).(28) Average completion time was 14 minutes (median 12 min., range 4-59 min.). Table 1 provides sociodemographic and economic characteristics of the 423 respondents. Our sample was generally younger, more educated, and lower income than the state population. The proportion of respondents identifying as heterosexual was significantly lower (81.1\%) than population estimates for GA (95.1\%). See Additional File 3 for further comparisons between sample characteristics and state estimates.

[insert Table 1]

\section{Quantitative analysis}

The COVID-19 pandemic impacted respondents across all domains: work life, home life, wellbeing, COVID-19 infection, and partner abuse (Table 2). Twenty-two percent had experienced job loss $(n=93)$. Nearly one-third $(n=132,31.2 \%)$ stated that they were unable to pay bills; 1 in 5 households $(n=85,20.1 \%)$ reported food shortages. Of the respondents with children, $75.8 \%(n=160 / 211)$ had to take over teaching their children from home. Most respondents reported increases in mental health issues and sleep problems; physical health problems and substance use reportedly increased. Thirty individuals in our sample (7.1\%) had tested positive for COVID-19. Every $5^{\text {th }}$ person had lost a family member or close friend to COVID-19 infection ( $\left.n=75,17.8 \%\right)$. Twenty-one women (5.0\%) were currently exposed to intimate partner violence (IPV).

[insert Table 2]

Frequencies of responses were analyzed further in a latent class analysis (LCA). Results of the LCA revealed a potential fit of a 2class, 4-class, and 5-class model, given the superior values of various indices (Table 3). However, the 4-class model was selected as 
the optimal model as it had the lowest Bayesian Information Criterion (BIC). The 4-class model had the highest BF at 3.244, conveying moderate evidence that this model is the most appropriate fit for the data. Although the 2-class model had a slightly higher entropy score, the 4-class model suggests a good separation of classes.

[insert Table 3]

Conditional item probabilities and class differences on sociodemographic and economic variables were used to further characterize and label the four classes (see Additional File 4). We labeled these classes as follows: Class 1 "Low exposure" to adverse experiences, Class 2 "High exposure", Class 3 "Caregiving stress," and Class 4 "Mental health changes." Figure 1 illustrates the likelihood of endorsing adverse pandemic-related experiences surrounding work life, home life, wellbeing, and COVID-19 infection for each of the classes. Table 4 shows the differences in sociodemographic characteristics for the four classes.

\section{Class 1 Low exposure}

Women in Class 1 ( $n=123,29.1 \%)$ had a relatively low probability of endorsing adverse experiences related to work life, home life, wellbeing, or COVID-19 infection. These women were generally older (30-49 years old), non-Hispanic white, and did not have children living in their home. Class 1 was most likely to have had a stable or increased household income during the pandemic. These women were least likely to have experienced IPV in their lifetimes.

\section{Class 2 High exposure}

Women in Class 2 ( $n=46,10.9 \%)$ were likely to have experienced multiple adverse outcomes during the pandemic. These women had the highest likelihood of reporting an inability to pay bills, increased conflict in the home, poor mental and physical health, and barriers to accessing health care. Furthermore, individuals in this class had the greatest probability of having had close or direct coronavirus exposure and of having lost a family member or friend due to COVID-19. Examining the demographics of women in Class 2 , they were more likely to identify with a sexual minority or a racial/ethnic minority population. They were least likely to have health insurance currently, they reported a lower household income since the pandemic, and they endorsed experiencing IPV during the pandemic.

\section{Class 3 Caregiving stress}

Women in Class 3 ( $n=104,24.6 \%)$ reported difficulties related to childcare, teaching children, and balancing work and caretaking. These women also endorsed experiencing poor mental and physical wellbeing during the pandemic. Demographically, Class 3 was older (30-49) and non-white. Similar to Class 2, these women reported experiencing IPV during the pandemic.

\section{Class 4 Mental health changes}

Women in Class 4 represented the largest group ( $n=150,35.5 \%)$. This subgroup had relatively low probability of endorsing adverse experiences in work/home life or with COVID-19 infection, yet they did report increased mental health challenges and unhealthy lifestyle changes. These women were least likely to be married/partnered, and they were more likely to identify with a sexual minority population.

[insert Figure 1] 
[insert Table 4]

Qualitative analysis

Participants were invited to expand on the pandemic's impact on their lives in an optional open-ended question. In total 330 women responded to the question. We excluded 21 responses that were deemed invalid or illogical by the researchers, leaving 309 valid responses (73.0\%). There was no significant difference between the proportion of classes that responded and did not respond to the question. Responses were primarily negative $(n=264,85.4 \%)$, followed by some that were neutral $(n=36,11.7 \%)$ or positive $(n=9$, 2.9\%). Predominant themes which emerged were stress, family, mental health, financial impact, and adaptation/resilience. Figure 2 provides anchor quotes from women in each of the 4 classes which convey identified themes.

[insert Figure 2]

\section{Discussion}

Women in our study were significantly impacted by the COVID-19 pandemic. Women who endorsed multiple adverse experiences (Class 2 High exposure) were significantly more likely to identify as Black and/or Hispanic, illustrating the pandemic's disproportionate impact on minority families. Individuals in Class 2 and Class 3 (Caregiving stress) had higher probabilities of experiencing IPV during the pandemic. Class 4 Mental health changes, the largest subgroup in our sample, was generally nonHispanic white; for this group, the pandemic exacerbated feelings of anxiety, isolation, panic, and depression. Nearly $30 \%$ of our sample had a low probability of endorsing adverse pandemic-related experiences (Class 1 Low exposure) and reported the same or even higher income than before the pandemic. Nonetheless, these women described family deaths, long-term COVID-19 symptoms, and damaged family relationships due to the pandemic.

Mental health issues were endorsed by more than $75 \%$ of individuals in our sample. Early data from the pandemic (March to June 2020) found that identifying as female is significantly associated with higher self-reported levels of stress, anxiety, depression, and posttraumatic stress symptoms, and more severe overall psychological impact of the pandemic. $(29,30)$ Furthermore, women who experience intimate partner violence are at high risk for developing mental health problems.(31) Lifetime prevalence of IPV in our sample was $25 \%$, comparable with pre-pandemic estimates for the US.(32) Numerous studies and reports attest to the "horrifying surge" in domestic violence across the globe. $(31,33)$ Five percent of our sample reported current IPV, and women who experienced abuse in the past are at increased risk of violence during the ongoing pandemic.(34) Given the stigma around mental health problems and the underreporting of domestic abuse, our data may not fully capture all adverse experiences of individuals in our sample. It is therefore of utmost importance that governments acknowledge the vulnerability of women and take action to improve conditions for women during the pandemic and beyond.(33)

COVID-19 affected respondents' immediate and extended family. Income loss was reported by $44.7 \%$ and job loss by $22.0 \%$. This corresponds with a national survey of US women in which $48.0 \%$ reported income loss and $22.9 \%$ job loss.(35) These financial problems have implications for paying bills, buying food, and paying for healthcare. Members of Class 2 (High exposure) in our study had the highest likelihood of reporting an inability to pay bills, food shortages, increased conflict in the home, poor mental and physical health, health insurance loss, and barriers to accessing health care. In the open text, individuals in Class 2 described reliance on extended family to avoid homelessness. Tragically, these individuals - who were the most impacted by the pandemic - were also most likely to have lost loved ones due to COVID-19.

Our qualitative and quantitative research substantiate the disparate experiences of minority populations compared to white, straight populations during the pandemic. Racial, ethnic and sexual minority populations in the US are at increased risk of severe COVID-19 disease; $(36,37)$ in addition, these populations carry a disproportionate burden of social, economic and health challenges which have been magnified through the pandemic. $(3,6,38)$ Minority populations in our sample were more likely to have serious, adverse experiences across multiple domains during COVID-19 than non-Hispanic white women straight women. Conversely, Class 1, which reported fewest negative experiences, was generally non-Hispanic white. These women had middle to high income prior to the 
pandemic, and stable or even increased income during the pandemic; they reported no IPV, very few personal losses to COVID-19, and limited barriers to the care that they needed.

Limitations

Findings from this study add to the body of literature on the impacts of the COVID-19 pandemic and associated sociodemographic disparities. However, limitations inherent to this study were, first, the use of internet-based recruitment, which may not be accessible to all Georgians. Second, non-probability sampling limits the generalizability of our findings. Third, our sample differed demographically from state statistics. Respondents were younger, more educated, and poorer than state estimates; this is likely due to one platform's strong base of university and college students and alumni in Georgia. Our survey was diverse, with $18.1 \%$ identifying with a sexual minority population. The proportion of lesbian and bisexual respondents was three times higher than general population estimates for Georgia,(39) although state-wide statistics may underestimate sexual minority membership in younger, female populations such as ours. $(6,40)$

\section{Conclusions}

Though many individuals in our sample experienced hardship, minority populations were most impacted by adverse experiences in work life, home life and wellbeing. Recovery efforts in Georgia must incorporate support mechanisms for mental health and IPV, focusing particularly on the needs of racial, ethnic, and sexual minority populations. Programs to prevent such catastrophic impacts from future emergencies must also center these populations' needs. Long term impacts of pandemic-related negative experiences, such as the loss of family and friends, financial issues, career setbacks, family struggles are still unknown. Broad dissemination of these findings outside of peer-reviewed literature may enable individuals to better characterize their own experiences during the pandemic and provide reassurance that they are not alone.

\section{Declarations}

Ethics approval and consent to participate: Emory University Institutional Review Board approved the study on May 19, 2020. All methods were carried out in accordance with relevant guidelines and regulations. Informed consent was obtained from all subjects and/or their legal guardian(s).

Consent for publication: Not applicable.

Availability of data and materials: All data generated or analyzed during this study are included in this published article and its additional files.

Competing interests: The authors declare that they have no competing interests.

Funding: This research was funded by the Executive Research Committee, Department of Gynecology and Obstetrics, Emory University School of Medicine.

Acknowledgements: The team would like to acknowledge Mugisha Niyibizi at the Georgia Clinical and Translational Science Alliance for her support in recruiting respondents. 
Authors' contributions: All authors contributed to the design of this study. MMM led the study, analyzed and interpreted the results, and prepared the manuscript. DG performed the latent class analysis and assisted with the figures. SC and DK contributed to the data collection, and the analysis and interpretation of the qualitative data. VJ and HG contributed to data acquisition, analysis, and manuscript preparation. PG conceptualized the study, guided survey development and recruitment, and revised the manuscript.

\section{References}

1. Johns Hopkins University \& Medicine. Coronavirus Resource Center 2021 [Available from: https://coronavirus.jhu.edu/map.html.

2. Bean M. States ranked by COVID-19 death rates: Oct. 29: Becker's Healthcare; 2021 [Available from: https://www.beckershospitalreview.com/public-health/us-coronavirus-deaths-by-state-july-1.html.

3. National Public Radio, Harvard TH Chan School of Public Health, Robert Wood Johnson Foundation. The Impact of Coronavirus on Households in Major US Cities 2020 [updated September. Available from: https://www.rwjf.org/en/library/research/2020/09/the-impact-of-coronavirus-on-households-across-america.html.

4. Madgavkar A, White O, Krishnan M, Mahajan D, Azcue X. COVID-19 and gender equality: Countering the regressive effects. 2020 Jul 15.

5. Kumar N. COVID 19 era: a beginning of upsurge in unwanted pregnancies, unmet need for contraception and other women related issues. Eur J Contracept Reprod Health Care. 2020;25(4):323-5.

6. Lindberg LD, VandeVusse A, Mueller J, Kirstein M. Early Impacts of the COVID-19 Pandemic: Findings from the 2020 Guttmacher Survey of Reproductive Health Experiences. New York; 2020.

7. Lindau ST, Makelarski JA, Boyd K, Doyle KE, Haider S, Kumar S, et al. Change in Health-Related Socioeconomic Risk Factors and Mental Health During the Early Phase of the COVID-19 Pandemic: A National Survey of U.S. Women. J Womens Health (Larchmt). 2021;30(4):502-13.

8. Quick Facts: Georgia: United States Census Bureau; [updated July 1, 2019. Available from: https://www.census.gov/data.html.

9. Eysenbach G. Improving the quality of Web surveys: the Checklist for Reporting Results of Internet E-Surveys (CHERRIES). J Med Internet Res. 2004;6(3):e34.

10. Grasso DJ, Briggs-Gowan MJ, Carter AS, Goldstein BL, Ford JD. Profiling COVID-related experiences in the United States with the Epidemic-Pandemic Impacts Inventory: Linkages to psychosocial functioning. Brain and Behavior. 2021;n/a(n/a):e02197.

11. Kraft JM, Snead MC, Brown JL, Sales JM, Kottke MJ, Hatfield-Timajchy K, et al. Reproductive Coercion Among African American Female Adolescents: Associations with Contraception and Sexually Transmitted Diseases. J Womens Health. 2021;30(3):429-37.

12. Weller BE, Bowen NK, Faubert SJ. Latent Class Analysis: A Guide to Best Practice. Journal of Black Psychology. 2020;46(4):287-311.

13. Hagenaars JA, McCutcheon AL. Applied Latent Class Analysis: Cambridge University Press; 2002.

14. Schwartz D. Annals of Statistics. 61978. p. 461-4.

15. Sclove SL. Application of model-selection criteria to some problems in multivariate analysis. Psychometrika. 1987;52(3):33343.

16. Bozdogan H. Model selection and Akaike's Information Criterion (AIC): The general theory and its analytical extensions. Psychometrika. 1987;52(3):345-70. 
17. Banfield JD, Raftery AE. Model-Based Gaussian and Non-Gaussian Clustering. Biometrics. 1993;49(3):803-21.

18. Masyn KE. Measurement Invariance and Differential Item Functioning in Latent Class Analysis With Stepwise Multiple Indicator Multiple Cause Modeling. Structural Equation Modeling: A Multidisciplinary Journal. 2017;24(2):180-97.

19. Nylund-Gibson K, Choi AY. Ten frequently asked questions about latent class analysis. Translational Issues in Psychological Science. 2018;4(4):440-61.

20. Lo Y, Mendell NR, Rubin DB. Testing the number of components in a normal mixture. Biometrika. 2001;88(3):767-78.

21. McLachlan G, Peel D. Finite Mixture Modeling. New York, NY: Wiley; 2000.

22. Wagenmakers E-J. A practical solution to the pervasive problems ofp values. Psychonomic Bulletin \& Review. 2007;14(5):779804.

23. Wasserman L. Bayesian Model Selection and Model Averaging. Journal of Mathematical Psychology. 2000;44(1):92-107.

24. Ramaswamy V, Desarbo WS, Reibstein DJ, Robinson WT. An Empirical Pooling Approach for Estimating Marketing Mix Elasticities with PIMS Data. Marketing Science. 1993;12(1):103-24.

25. Lanza ST, Tan X, Bray BC. Latent Class Analysis With Distal Outcomes: A Flexible Model-Based Approach. Structural Equation Modeling: A Multidisciplinary Journal. 2013;20(1):1-26.

26. Abdi H. The Bonferroni and Sidak corrections for multiple comparisons. Encyclopedia of Measurement and Statistics. Salkind, NJ: Sage Publishing; 2007.

27. Mayring P. Qualitative content analysis: theoretical foundation, basic procedures and software solution. Klagenfurt2014.

28. Chambers S, Nimon K, Anthony-McMann P. A primer for conducting survey research using MTurk: Tips for the field. International Journal of Adult Vocational Education and Technology. 2016;7(2).

29. Liu N, Zhang F, Wei C, Jia Y, Shang Z, Sun L, et al. Prevalence and predictors of PTSS during COVID-19 outbreak in China hardest-hit areas: Gender differences matter. Psychiatry Res. 2020;287:112921.

30. Wang C, Pan R, Wan X, Tan Y, Xu L, Ho CS, et al. Immediate Psychological Responses and Associated Factors during the Initial Stage of the 2019 Coronavirus Disease (COVID-19) Epidemic among the General Population in China. Int J Environ Res Public Health. 2020;17(5).

31. Almeida M, Shrestha AD, Stojanac D, Miller LJ. The impact of the COVID-19 pandemic on women's mental health. Arch Womens Ment Health. 2020;23(6):741-8.

32. World Health Organization. Violence against Women Prevalence Estimates, 2018. Geneva, CH; 2021.

33. Guterres A. Make the prevention and redress of violence against women a key part of national response plans for COVID-19, 6 April 20202020 [cited 2021 Dec 6]. Available from: https://www.un.org/en/un-coronavirus-communications-team/make-preventionand-redress-violence-against-women-key-part.

34. Sediri S, Zgueb Y, Ouanes S, Ouali U, Bourgou S, Jomli R, et al. Women's mental health: acute impact of COVID-19 pandemic on domestic violence. Arch Womens Ment Health. 2020;23(6):749-56.

35. Diamond-Smith N, Logan R, Marshall C, Corbetta-Rastelli C, Gutierrez S, Adler A, et al. COVID-19's impact on contraception experiences: Exacerbation of structural inequities in women's health. Contraception. 2021;104(6):600-5.

36. Heslin K, Hall J. Sexual Orientation Disparities in Risk Factors for Adverse COVID-19-Related Outcomes, by Race/Ethnicity Behavioral Risk Factor Surveillance System, United States, 2017-2019. Atlanta, GA: U.S. Department of Health and Human Service; 2021. 
37. Prevention CfDCa. Risk for COVID-19 Infection, Hospitalization, and Death By Race/Ethnicity Atlanta, GA2021 [Available from: https://www.cdc.gov/coronavirus/2019-ncov/covid-data/investigations-discovery/hospitalization-death-by-race-ethnicity.html.

38. Lin TK, Law R, Beaman J, Foster DG. The impact of the COVID-19 pandemic on economic security and pregnancy intentions among people at risk of pregnancy. Contraception. 2021;103(6):380-5.

39. The Williams Institute UCLA School of Law. LGBT Demographic Data Interactive Los Angeles2019 [cited 2020 July 15$].$ Available from: https://williamsinstitute.law.ucla.edu/quick-facts/us-state-data/.

40. Jones JM. LGBT Identification Rises to 5.6\% in Latest U.S. Estimate: Gallup, Inc.; 2021 [Available from: https://news.gallup.com/poll/329708/lgbt-identification-rises-latest-estimate.aspx.

\section{Tables}

Table 1. Sociodemographic and economic characteristics of survey respondents, Georgia US, 2020 (n=423) 
N (\%)

\begin{tabular}{|c|c|}
\hline \multicolumn{2}{|l|}{ Age (years) } \\
\hline $18-25$ & $81(19.1)$ \\
\hline $26-30$ & $79(18.7)$ \\
\hline $31-35$ & $110(26.0)$ \\
\hline $36-40$ & $63(14.9)$ \\
\hline $41-45$ & $63(14.9)$ \\
\hline $46-49$ & $27(6.4)$ \\
\hline \multicolumn{2}{|l|}{ Race } \\
\hline White & $249(58.9)$ \\
\hline Black & $125(29.6)$ \\
\hline Asian & $29(6.9)$ \\
\hline Other or multiple races & $17(4.0)$ \\
\hline Decline to answer & $3(0.7)$ \\
\hline \multicolumn{2}{|l|}{ Ethnicity } \\
\hline Non-Hispanic & $385(91.0)$ \\
\hline Hispanic & $32(7.6)$ \\
\hline Decline to answer & $6(1.4)$ \\
\hline \multicolumn{2}{|l|}{ Gender } \\
\hline Female & $420(99.3)$ \\
\hline Non-Binary & $3(0.7)$ \\
\hline \multicolumn{2}{|l|}{ Sexual orientation } \\
\hline Heterosexual & $343(81.1)$ \\
\hline Bisexual & $52(12.3)$ \\
\hline Homosexual & $15(3.5)$ \\
\hline Other & $12(2.8)$ \\
\hline Decline to answer & $1(0.2)$ \\
\hline \multicolumn{2}{|l|}{ Education level } \\
\hline High school/GED & $58(13.7)$ \\
\hline Associates degree/some college & $125(29.6)$ \\
\hline Bachelor's degree & $122(28.8)$ \\
\hline Graduate degree & $117(27.7)$ \\
\hline Decline to answer & $1(0.2)$ \\
\hline \multicolumn{2}{|l|}{ Relationship status } \\
\hline Partnered or married & $268(63.4)$ \\
\hline Single, separated, divorced & $154(36.4)$ \\
\hline Decline to answer & $1(0.2)$ \\
\hline
\end{tabular}

Page $11 / 17$ 
Children living in home

\begin{tabular}{ll} 
No & $212(50.1)$ \\
Yes & $211(49.9)$ \\
\hline $\begin{array}{l}\text { Income level } \\
\text { High }\end{array}$ & $139(32.9)$ \\
$\quad$ Middle & $118(27.9)$ \\
Low & $117(27.7)$ \\
$\quad$ Don't know / decline to answer & $49(11.5)$ \\
\hline $\begin{array}{l}\text { Monthly household income } \\
\text { Has decreased }\end{array}$ & $189(44.7)$ \\
Has remained the same & $175(41.4)$ \\
Has increased & $53(12.5)$ \\
$\quad$ Decline to answer & $6(1.4)$ \\
\hline Health insurance & \\
Currently have health insurance & $353(83.5)$ \\
Lost health insurance due to COVID-19 & $20(4.7)$ \\
Lost health insurance, other reason & $46(10.9)$ \\
Decline to answer & $4(0.9)$
\end{tabular}

Table 2. Frequencies of responses to questions about COVID-19 impact on work life, home life, wellbeing, infection and partner abuse, Georgia US, 2020 (n=423) 
N (\%)

\begin{tabular}{|c|c|}
\hline \multicolumn{2}{|l|}{ Work life $(n=423)$} \\
\hline Laid off & $93(22.0)$ \\
\hline Reduced work hours & $163(38.5)$ \\
\hline Continued working despite exposure & $194(45.9)$ \\
\hline Hard time working from home & $146(34.5)$ \\
\hline Hard time working due to caretaking & $146(34.5)$ \\
\hline Difficulty with transportation & $93(22.0)$ \\
\hline Unable to pay bills & $132(31.2)$ \\
\hline Difficulty getting food or healthy food & $85(20.1)$ \\
\hline \multicolumn{2}{|l|}{ Home life $(n=211)^{*}$} \\
\hline Having to take over teaching children & $160(75.8)$ \\
\hline Childcare unavailable & $108(51.2)$ \\
\hline Difficulty taking care of children & $105(49.8)$ \\
\hline Increased conflict with children & $77(36.5)$ \\
\hline Increased conflict among children & $77(36.5)$ \\
\hline Increased conflict with adults ${ }^{\star \star}$ & $105(24.8)$ \\
\hline \multicolumn{2}{|l|}{ Wellbeing $(n=423)$} \\
\hline Increased physical health problems & $125(29.6)$ \\
\hline Increased mental health problems & $327(77.3)$ \\
\hline Increased sleep problems & $299(70.7)$ \\
\hline Increased alcohol/substance use & $119(28.1)$ \\
\hline Less physical activity & $283(66.9)$ \\
\hline Overeating & $276(65.2)$ \\
\hline Barriers to healthcare & $60(14.2)$ \\
\hline Barriers to mental health services & $86(20.3)$ \\
\hline Less routine healthcare & $216(51.1)$ \\
\hline Unable to get medications & $61(14.4)$ \\
\hline \multicolumn{2}{|l|}{ COVID-19 infection $(n=423)$} \\
\hline Tested positive for COVID-19 & $30(7.1)$ \\
\hline Had COVID-19 symptoms but never tested & $40(9.5)$ \\
\hline Provided direct care to COVID-19+ & $46(10.9)$ \\
\hline Provided supportive care to COVID-19+ & $55(13.0)$ \\
\hline Death of family/friend due to COVID-19 & $75(17.8)$ \\
\hline \multicolumn{2}{|l|}{ Partner abuse $(n=423)$} \\
\hline Lifetime intimate partner violence & $106(25.1)$ \\
\hline Current intimate partner violence & $21(5.0)$ \\
\hline
\end{tabular}

Page 13/17 
* Denominator of $n=211$ representing those respondents who reported having children.

** Denominator of $n=423$, including all respondents with or without children

Table 3. Fit statistics and classification coefficients for latent class analysis

\begin{tabular}{|c|c|c|c|c|c|c|c|c|c|c|c|}
\hline & $\mathrm{d}$ & & $\mathrm{BIC}$ & $S A B$ & CAIC & AWE & & & & $B F$ & $\mathrm{cmP}$ \\
\hline 1 Class & 32 & -6914.01 & 14021.54 & 13919.99 & 13944.06 & 13960.06 & - & - & 0.000 & - & .000 \\
\hline $\begin{array}{l}2 \\
\text { Classes }\end{array}$ & 65 & -6285.78 & 12964.64 & 12758.37 & 12807.27 & 12839.77 & $<.001$ & $<.001$ & 0.000 & .899 & .000 \\
\hline $\begin{array}{l}3 \\
\text { Classes }\end{array}$ & 98 & -6095.32 & 12783.29 & 12472.30 & 12546.02 & 12595.02 & $<.001$ & .008 & 0.005 & .884 & .049 \\
\hline $\begin{array}{l}4 \\
\text { Classes }\end{array}$ & 131 & -5943.47 & 12678.68 & 12262.97 & 12361.99 & 12427.49 & $<.001$ & .148 & 3.244 & .887 & .455 \\
\hline $\begin{array}{l}5 \\
\text { Classes }\end{array}$ & 164 & -5855.23 & 12702.22 & 12181.79 & 12305.18 & 12387.18 & $<.001$ & .577 & - & .885 & .484 \\
\hline $\begin{array}{l}6 \\
\text { Classes }\end{array}$ & 197 & - & - & - & - & - & - & - & - & - & - \\
\hline $\begin{array}{l}7 \\
\text { Classes }\end{array}$ & 230 & - & - & - & - & - & - & - & - & - & - \\
\hline
\end{tabular}

Note. $\mathrm{d}$ = number of parameters; $\mathrm{LL}=$ log-likelihood; $\mathrm{BIC}=$ Bayesian Information Criterion; SABIC = Sample size adjusted BIC; CAIC = Consistent Akaike Information Criterion; AWE = Approximate Weight of Evidence Criterion; VLRM-LRT = Vuong-LoMendell-Rubin adjusted likelihood ratio test; $p=p$-value; $B F=$ Bayes Factor; $c m P=$ correct model probability. Bold values indicate superior fit for each statistic. 
Table 4. Class Comparisons

\begin{tabular}{llllllll} 
Class 1 & \multicolumn{1}{l}{ Class 2} & \multicolumn{1}{l}{ Class 3} & Class 4 & & \\
Prob SE & Prob SE & Prob SE & Prob SE & $\chi^{2}$ & Class Differences
\end{tabular}

Sociodemographic Characteristics

Age group

$\begin{array}{lllllllllll}18-30 & 0.40 & 0.06 & 0.32 & 0.09 & 0.15 & 0.04 & 0.55 & 0.06 & & \\ 31-49 & 0.60 & 0.06 & 0.69 & 0.09 & 0.85 & 0.04 & 0.45 & 0.06 & 32.96^{* *} & \text { C3>C1,C4; C2>C4 }\end{array}$

Race/Ethnicity

$\begin{array}{lllllllllll}\text { Non-Hispanic White } & 0.61 & 0.05 & 0.34 & 0.08 & 0.44 & 0.05 & 0.69 & 0.05 & & \\ \text { Non-White } & 0.40 & 0.05 & 0.67 & 0.08 & 0.56 & 0.05 & 0.41 & 0.05 & 14.56^{*} & \text { C2,C3>C1,C4 }\end{array}$

Setting

$\begin{array}{lllllllllll}\text { Urban/Suburban } & 0.75 & 0.06 & 0.73 & 0.09 & 0.76 & 0.05 & 0.89 & 0.03 & & \\ \text { Rural } & 0.25 & 0.06 & 0.27 & 0.09 & 0.24 & 0.05 & 0.11 & 0.03 & 9.66^{*} & \mathrm{C} 1, \mathrm{C} 3>\mathrm{C} 4\end{array}$

Children in Home

$\begin{array}{lllllllllll}\text { No } & 0.80 & 0.06 & 0.00 & 0.00 & 0.00 & 0.00 & 0.95 & 0.03 & & \\ \text { Yes } & 0.20 & 0.06 & 1.00 & 0.00 & 1.00 & 0.00 & 0.05 & 0.03 & 1621.27 * \star & \mathrm{C} 2, \mathrm{C} 3>\mathrm{C} 1, \mathrm{C} 4 ; \mathrm{C} 1>\mathrm{C} 4\end{array}$

Insurance

$\begin{array}{llllllllllll}\text { No } & 0.13 & 0.05 & 0.41 & 0.08 & 0.07 & 0.03 & 0.16 & 0.04 & & \\ \text { Yes } & 0.87 & 0.05 & 0.59 & 0.08 & 0.93 & 0.03 & 0.87 & 0.04 & 17.27 * & \mathrm{C} 1, \mathrm{C} 3, \mathrm{C} 4>\mathrm{C} 2\end{array}$

Sexual orientation

\begin{tabular}{lllllllllll} 
Heterosexual & 0.91 & 0.03 & 0.54 & 0.09 & 0.93 & 0.03 & 0.73 & 0.05 & & \\
\hline Bi/homosexual/other & 0.09 & 0.03 & 0.46 & 0.09 & 0.07 & 0.03 & 0.27 & 0.05 & $23.16^{* *}$ & C2,C4>C1,C3
\end{tabular}

Relationship status

Single/separated

$\begin{array}{llllllll}0.34 & 0.05 & 0.29 & 0.10 & 0.24 & 0.05 & 0.50 & 0.05\end{array}$

Partnered/married

$0.66 \quad 0.05 \quad 0.71$

0.10

$0.76 \quad 0.05$

$0.50 \quad 0.0513 .37 *$

$\mathrm{C} 1, \mathrm{C} 2, \mathrm{C} 3>\mathrm{C} 4$

Highest education

$\begin{array}{lllllllllll}\text { No graduate degree } & 0.38 & 0.21 & 0.65 & 0.09 & 0.49 & 0.51 & 0.36 & 0.06 & & \\ \geq \text { Bachelor's degree } & 0.62 & 0.21 & 0.35 & 0.09 & 0.51 & 0.11 & 0.64 & 0.06 & 7.61 & n s\end{array}$

Income

$\begin{array}{lllllllllll}\text { Low } & 0.25 & 0.07 & 0.49 & 0.09 & 0.31 & 0.07 & 0.30 & 0.06 & & \\ \text { Middle/High } & 0.75 & 0.07 & 0.51 & 0.09 & 0.69 & 0.07 & 0.70 & 0.06 & 4.74 & n s\end{array}$

Income change

$\begin{array}{lllllllllll}\text { Lower than before } & 0.24 & 0.06 & 0.81 & 0.07 & 0.54 & 0.06 & 0.46 & 0.07 & & \\ \text { Same or higher } & 0.76 & 0.06 & 0.19 & 0.07 & 0.46 & 0.06 & 0.55 & 0.07 & 47.79 * \star & \mathrm{C} 1>\mathrm{C} 2, \mathrm{C} 3, \mathrm{C} 4 ; \mathrm{C} 3, \mathrm{C} 4>\mathrm{C} 2\end{array}$

Current IPV

$\begin{array}{lllllllllll}\text { No } & 1.00 & 0.00 & 0.88 & 0.05 & 0.88 & 0.04 & 0.98 & 0.01 & & \\ \text { Yes } & 0.00 & 0.00 & 0.12 & 0.05 & 0.12 & 0.04 & 0.02 & 0.01 & 22.18^{* *} & \text { C2,C3>C } 1, \mathrm{C} 4\end{array}$


Lifetime IPV

\begin{tabular}{lllllllllll}
\hline No & 0.94 & 0.03 & 0.59 & 0.09 & 0.68 & 0.06 & 0.68 & 0.05 & & \\
\hline Yes & 0.06 & 0.03 & 0.41 & 0.09 & 0.32 & 0.06 & 0.33 & 0.05 & $45.57^{\star *}$ & C2,C3,C4>C1
\end{tabular}

IPV = intimate partner violence

Note. Class differences represent pairwise comparisons that are significant after Bonferroni adjustment.

${ }^{\star} p<.01,{ }^{\star *} p<.001$

\section{Figures}

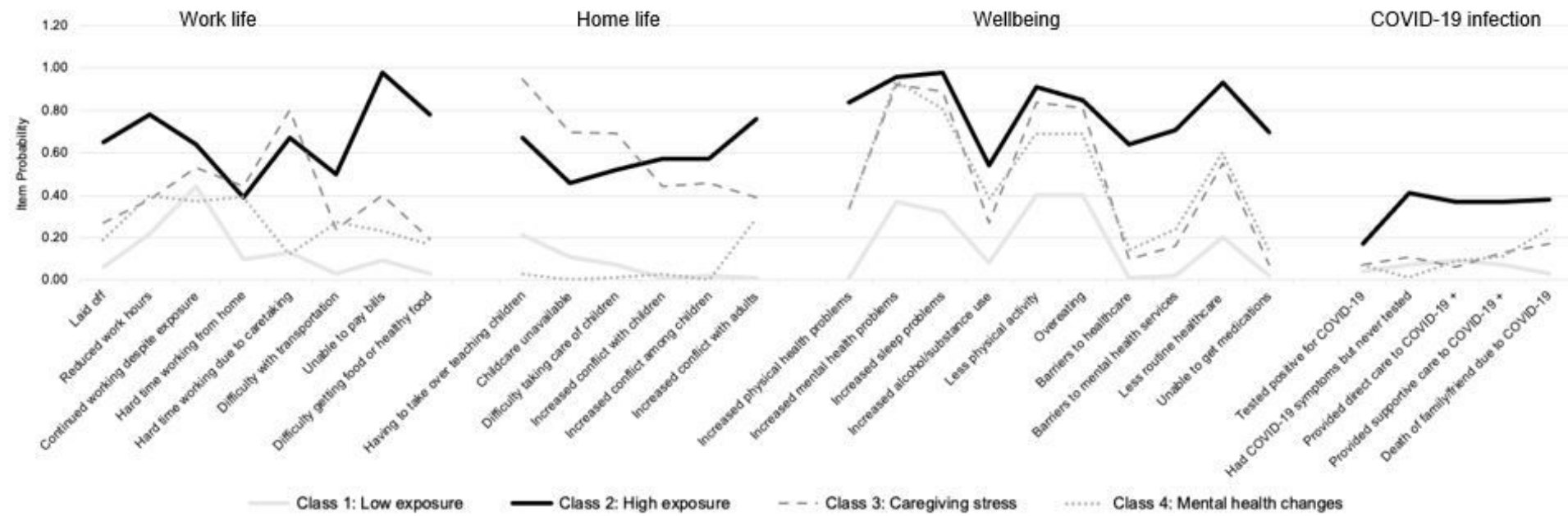

\section{Figure 1}

Probability of adverse experiences endorsed by women during the COVID-19 pandemic ( $n=423$ respondents). Probabilities of adverse experiences surrounding work life, home life, wellbeing and COVID-19 infection were generally lowest for Class 1 and highest for Class 2. Members of Class 3 had high probabilities of endorsing challenges in caring for family members, while women in Class 4 reported negative experiences related to their mental and/or physical wellbeing. 


\begin{tabular}{|c|c|}
\hline \multirow{3}{*}{ 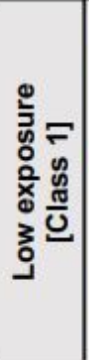 } & $\begin{array}{l}\text { Fortunately, I have not had any family members become ill with COVID-19. We all practice } \\
\text { CDC sponsored guidelines. However, it is isolating to spend so much time without just the } \\
\text { day-to-day interactions with others. I try to keep a positive attitude, but it can be hard to stay } \\
\text { hopeful during these times. }\end{array}$ \\
\hline & $\begin{array}{l}\text { I lost my grandmother to COVID-19, which has been sad for my family. We have not visited } \\
\text { the typical things a 3-year-old and baby visit, such as the library, discovery museum, indoor } \\
\text { play places, dance lessons, visiting family, and shopping as I want to protect my children. }\end{array}$ \\
\hline & $\begin{array}{l}\text { I had COVID-19 and have had ongoing symptoms continuing for } 6 \text { months, so my life was } \\
\text { significantly impacted by COVID-19 due to major change in my health. After having COVID- } \\
19 \text {, it is hard on your mental health to have people doubting the seriousness of the illness and } \\
\text { effects and is hurtful. COVID-19 and the politics related have estranged many relationships } \\
\text { with family and friends. }\end{array}$ \\
\hline \multirow{5}{*}{ 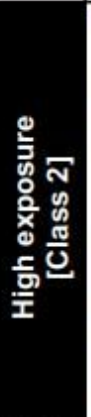 } & $\begin{array}{l}\text { Horrible impact. I got laid off due to COVID-19. I no longer have health insurance. I'm on the } \\
\text { verge of not being able to pay my bills. }\end{array}$ \\
\hline & $\begin{array}{l}\text { I had to move back from college to my parents' house. I tried to kill myself because my dad } \\
\text { sucks, and I wasn't able to go to therapy or get my meds. }\end{array}$ \\
\hline & $\begin{array}{l}\text { My husband and I both lost our jobs. We lost our home. Our kids went to virtual school and } \\
\text { they're going to fail, I just know it. I'm worried sick. }\end{array}$ \\
\hline & $\begin{array}{l}\text { I had to switch to less expensive medicine for my depression, anxiety, and ADHD when I lost } \\
\text { my insurance because the ones that work best for me cost } \$ 725 \text { per month without the } \\
\text { insurance. I currently have gynecological issues but I can't get them evaluated because I have } \\
\text { no health insurance. }\end{array}$ \\
\hline & $\begin{array}{l}\text { We have had to live in my fiancé's mother's house. She has family over visiting constantly. } \\
\text { They steal our things, do not socially distance and some are addicted to drugs. We are not } \\
\text { safe here, I hate it. }\end{array}$ \\
\hline \multirow{4}{*}{ 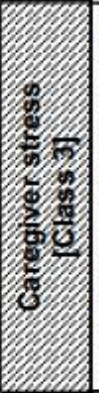 } & $\begin{array}{l}\text { I feel overwhelmed and exhausted. Trying to parent and teach while maintaining a household } \\
\text { is draining. I don't know how much more I can take. }\end{array}$ \\
\hline & $\begin{array}{l}\text { This pandemic as increased my anxiety and fear as well as stress. I am struggling to put food } \\
\text { on the table and pay bills because the kids are home } 24-7 \text {. Our grocery bill increased to } \\
\text { almost } \$ 800 \text { a month. }\end{array}$ \\
\hline & $\begin{array}{l}\text { Kids were out of school for a while; I had to leave my job and move } 4 \text { hours away to live with } \\
\text { my mother, found a job then had to leave it due to pandemic; had to pawn my vehicle title for } \\
\text { money to buy Christmas presents for my son and food. There was more that's not on the top } \\
\text { of my head... }\end{array}$ \\
\hline & $\begin{array}{l}\text { Loss of job and home had to move in with boyfriend with my } 4 \text { kids while I was pregnant with a } \\
5 \text { th, unemployment so low can't pay my bills, scared to get a job due to child with severe } \\
\text { asthma and an infant. }\end{array}$ \\
\hline \multirow{5}{*}{ 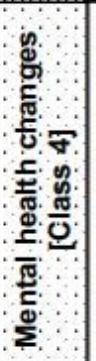 } & $\begin{array}{l}\text { Worsened preexisting chronic depression. Feelings of isolation, hopelessness, confusion, } \\
\text { fatigue, overeating. Anxiety about losing job }\end{array}$ \\
\hline & $\begin{array}{l}\text { I went through a very deep major depression, joined a moderation group for alcohol, changed } \\
\text { my wedding. This has seriously affected my mental health. I've put off dental treatment as well } \\
\text { despite pain. }\end{array}$ \\
\hline & $\begin{array}{l}\text { It resulted in the loss of my grandfather. My anxiety has increased. But it's brought me closer } \\
\text { to my family and partner. }\end{array}$ \\
\hline & $\begin{array}{l}\text { It's affected us mentally more than anything. I was diagnosed with severe/moderate } \\
\text { depression, other family members are experiencing anxiety. }\end{array}$ \\
\hline & $\begin{array}{l}\text { Several funerals, very few family visits, delay surgical procedures for older members, financial } \\
\text { and emotional stress, panic/depression in kids/adults }\end{array}$ \\
\hline
\end{tabular}

Figure 2

Women's descriptions of pandemic's impact on their lives. Selected anchor quotes from 309 responses that illustrate a commonality of themes - stress, family, mental health, financial impact, and adaption/resilience - and simultaneously the distinct experiences among women in each class.

\section{Supplementary Files}

This is a list of supplementary files associated with this preprint. Click to download.

- Additionalfile1SampleAdvertisementonFacebook.jpg

- Additionalfile2COVID19survey.pdf

- Additionalfile3ComparisonofStudySampleandStateDemographicCharacteristics.docx

- Additionalfile4/temProbabilitiesandEntropyScores.docx 